\title{
Inovando no ensino de administração: uma experiência com a aprendizagem baseada em problemas (PBL)
}

\author{
Innovating in the teaching of business administration: an experiment with \\ problem-based learning (PBL)
}

\author{
Edmundo Escrivão Filho ${ }^{7}$ \\ Luis Roberto de Camargo Ribeiro ${ }^{2}$
}

\section{Resumo:}

O objetivo deste artigo é relatar uma experiência educacional inovadora de ensino-aprendizagem de administração em disciplinas de graduação e pós-graduação com a aprendizagem baseada em problemas ou PBL (problem-based learning), como é mundialmente conhecida. A experiência ocorreu numa escola de engenharia de uma universidade pública, em diversos cursos de graduação em engenharia e em disciplinas de pós-graduação. Todas as disciplinas tinham conteúdos de administração, especificamente de "teoria geral da administração" e "introdução à administração". O estudo almeja substituir abordagens didáticas tradicionais e a construção conjunta da mudança entre professor/tutor e alunos. A adoção do PBL foi motivada pelo descompasso entre as exigências e dinâmica da vida profissional e a passividade e alienação dos alunos em sala de aula. A avaliação geral do professor e de $90 \%$ dos alunos é que o PBL tem bom resultado na aprendizagem de conceitos, habilidades e atitudes.

Palavras-chave: ensino de administração; aprendizagem baseada em problemas; ensino superior.

\begin{abstract}
:
The goal of this article is to present an educational experiment in the teaching and learning of administration with problem-based learning (PBL) at the undergraduate and graduate levels. The experiment has taken place in a school of engineering at a public university in Brazil in several modules that covered business administration contents, especially "general administration theory" and "introduction to administration". This study intended to facilitate the replacement of traditional didactic approaches and the collective construction of this change by the teacher/tutor and students. The adoption of PBL was motivated by the increasing dissociation between the demands and dynamics of professional life and students' passivity and alienation in the classroom. The teacher in charge of the modules and $90 \%$ of the students indicate that PBL promotes the learning of concepts, skills and attitudes.
\end{abstract}

Key words: teaching of administration; problem-based learning; higher education.

\section{Introdução}

A educação superior está numa encruzilhada. Muitos fatores a colocam nessa posição e a pressionam por mudanças; entre eles, o crescimento extraordinário do volume de conhecimentos que devem ser apresentados e apreendidos pelos alunos durante sua formação e, em contrapartida, sua rápida obsolescência. Assim, não basta mais ensinar conteúdos fixos e acabados durante a educação profissional, pois se sabe que muito desse

1 Professor na Escola de Engenharia de São Carlos (EESC) da Universidade de São Paulo (USP). Doutor em Engenharia de Produção pela Universidade Federal de Santa Catarina - UFSC. Endereço: Av. Trabalhador São Carlense, 400 - Centro - São Carlos/São Paulo - Brasil -CEP: 13566-590. Email: edesfi@sc.usp.br

2 Pesquisador associado junto ao Departamento de Metodologia de Ensino da Universidade Federal de São Carlos e tutor na UAB (Universidade Aberta do Brasil) . PhD em Educação pela Universidade Federal de São Carlos. Endereço: Rua Dr Donato Ferreira dos Santos 335 - Nova Sta Paula - São Carlos/São Paulo - Brasil CEP: 13564-410 . Email: luisrcr@itelefonica.com.br

Artigo submetido em julho de 2007 e aceito em maio de 2008 
conhecimento estará desatualizado já no momento em que os formandos estiverem ingressando no mercado do trabalho. É preciso promover nos alunos a autonomia na aprendizagem, para que possam buscar e criar novos conhecimentos durante toda sua vida profissional.

Por outro lado, tem-se a complexidade do mundo do trabalho e outros fatores econômicos, sociais e históricos. Há muito tempo, alunos de cursos superiores não têm mais sua colocação assegurada após a diplomação. O mercado de trabalho não emprega tanto quanto no passado devido a três fatores principais: as sucessivas crises econômicas inerentes ao sistema capitalista (i.e., desemprego clássico), a crescente substituição de mão-de-obra por tecnologia (i.e., desemprego estrutural) e a adoção de novos modelos de gestão empresarial, que afetam, sobretudo, as camadas intermediárias da pirâmide organizacional, diminuindo principalmente as oportunidades de emprego de engenheiros e administradores nos níveis inferior e médio de gerência.

Como conseqüência dessa conjuntura, emprego garantido após a graduação e longa carreira numa só empresa, ou mesmo numa única especialidade, são perspectivas cada vez mais improváveis. Hoje, é comum engenheiros e administradores atuarem, ao longo de suas carreiras, em várias áreas da mesma organização (e.g., marketing, produção, vendas, finanças), em várias empresas de um mesmo setor ou de setores produtivos diferentes, e eventualmente virem a iniciar seu próprio empreendimento. Daí a importância dos alunos do ensino superior e profissionalizante, além de adquirirem uma sólida base técnico-científica, desenvolverem outros tipos de conhecimentos: procedimentais e atitudinais.

De fato, muitos levantamentos de perfis profissionais têm apontado para a necessidade das escolas e universidade atentarem para a promoção de outros conhecimentos, como capacidade de resolução de problemas e de estudo independente, habilidade para o trabalho em grupo, sensibilidade para os impactos de sua prática no ambiente e na sociedade, colaboração, ética profissional e cidadania. Ter esses atributos implica uma educação superior/profissionalizante mais abrangente do que a que vigora em muitas escolas. Demanda mudanças em todos os níveis do processo educacional: desde a concepção dos objetivos educacionais, passando pela elaboração dos requisitos para o reconhecimento dos programas e a operacionalização das diretrizes curriculares, até a capacitação de professores e o desenvolvimento e adoção de metodologias de ensino inovadoras.

No nível da sala de aula universitária, essas mudanças constituem um grande desafio, já que não é preciso um diagnóstico sistemático para constatar a predominância de métodos tradicionais, nos quais o professor é colocado num pedestal e os alunos são vistos como caixas vazias a receber um conhecimento fixo e acabado, autoritária e passivamente distribuído. Nesses modelos, predomina aquilo que Freire (1981, p.38) chama de “consciência bancária”. Nessa perspectiva educacional " "pensa[-se] que quanto mais se dá, mais se sabe'. Mas a experiência revela que com este mesmo sistema só se formam indivíduos medíocres, porque não há estímulo para a criação".

Para transformar o status quo da sala de aula universitária é urgente repensar os objetivos educacionais, visando à adoção de abordagens alternativas ao ensino tradicional que atentem para a aquisição de outros conteúdos, além dos técnico-científicos, sem sobrecarregar nem ampliar exageradamente os currículos. Nesse sentido, universidades e faculdades têm lançado mão de metodologias integrativas e construtivistas, como o PBL, que promovem a aquisição de conceitos e o desenvolvimento de habilidades e atitudes de forma integrada, sem a necessidade de conceber disciplinas especialmente com esse objetivo (SAVIN-BADEN, 2000).

\section{A aprendizagem baseada em problemas (PBL)}

A aprendizagem baseada em problemas ou PBL (problem-based learning) é uma metodologia de ensinoaprendizagem surgida na escola de medicina da Universidade McMaster, no Canadá, em meados dos anos 1960. O PBL tem sua fundamentação no pressuposto de que a aprendizagem não é um simples processo de recepção de informações, mas de construção de significados. Pauta-se por vários resultados de pesquisas da psicologia cognitiva. Entre eles, parte da premissa de que a aprendizagem acontece, principalmente, quando se lança mão dos conhecimentos prévios do aluno; ou seja, de estratégias de estudo que promovam a elaboração das informações e sua incorporação por estruturas cognitivas existentes, transformando-as (RIBEIRO, 2008). 
O PBL baseia-se igualmente na perspectiva de otimização da aprendizagem, por meio do desenvolvimento, nos alunos, da metacognição e de habilidades de trabalho em grupo. Segue as indicações de educadores e pesquisadores educacionais que acreditam na influência das interações sociais na construção do conhecimento e no significado moderno do conhecimento, a saber: um consenso provisório, social e historicamente determinado, sobre o que constitui a realidade. Está particularmente associada às teorias de Dewey (1964) e de Bruner (1973), quando aponta para a importância do aprender em resposta a - e em interação com - a realidade, já que isso promove a motivação epistêmica dos alunos (i.e., a força interna que leva as pessoas a conhecer melhor o mundo em que vivem).

A despeito de sua origem no ensino de medicina, o PBL logo se expandiu para o ensino em outras áreas de conhecimento, como administração (e.g., STINSON; MILTER, 1996) e engenharia (e.g., DENAYER et al, 2003), e para outros níveis educacionais. Essencialmente, o PBL é uma abordagem que utiliza problemas para iniciar, enfocar e motivar a aprendizagem de conhecimentos social e profissionalmente relevantes. No modelo original PBL (McMaster), esses problemas formam a espinha dorsal do currículo e são trabalhados em pequenos grupos de alunos, aos quais, facilitados por um tutor, cabe buscar o conhecimento necessário para sua solução.

No entanto, à medida que foi sendo utilizado em outros contextos educacionais, o PBL sofreu adaptações. Há casos em que é adotado de forma híbrida (e.g., KINGSLAND, 1993), quando um núcleo central do currículo é voltado para a solução de problemas, informado por um conjunto de disciplinas trabalhadas pelos docentes responsáveis, da forma que estes julguem mais adequada. O PBL também vem sendo aplicada em disciplinas isoladas dentro de currículos tradicionais, bem como em determinados momentos no ensino de disciplinas trabalhadas convencionalmente (aulas expositivas), quando se pretende aprofundar um determinado tópico.

Ainda se discute se algumas características do formato PBL original são negociáveis. Parece não existir consenso sobre o quanto o PBL se distancia do modelo McMaster ao ser adotado nos diversos contextos educacionais e ainda ser vista como tal. Embora não esteja no escopo deste artigo discutir se modelos diferentes do original devem ou não ser considerados PBL, aqui seguem as indicações encontradas na literatura específica (e.g., DUCH; GROH; ALLEN, 2001) e os critérios de aceitação de trabalhos em congressos específicos sobre essa metodologia (e.g., INTERNATIONAL PBL CONFERENCE, 2006).

Em geral, entende-se que num ambiente de aprendizagem PBL, um problema de fim aberto - i.e., que não comporta apenas uma solução e demanda alguma integração de conteúdos disciplinares e/ou curriculares deve ser apresentado antes das teorias e conceitos necessários a sua compreensão e resolução serem buscados pelos alunos (em grupos autogeridos e facilitados por um tutor). Apesar de terem características similares, esta inversão problema-teoria é o que difere o PBL de outras metodologias de aprendizagem ativa, colaborativas, participativas, centradas no aluno ou no processo ou mesmo daquelas que envolvem a solução de problemas ou o trabalho com projetos.

Esse princípio é, de acordo com um dos pioneiros no uso dessa metodologia, Barrows (1996), o núcleo irredutível da aprendizagem baseada em problemas, como ilustra o ciclo de trabalho apresentado adiante. O processo PBL, necessariamente, inicia-se com a apresentação de um problema envolvendo conceitos não trabalhados anteriormente, o qual, os alunos (em grupos) tentam definir e solucionar valendo-se do conhecimento de que dispõem. A partir dessa discussão inicial, os alunos:

a) levantam hipóteses e as defendem, baseando-se nos dados apresentados no problema;

b) priorizam as hipóteses e determinam os conceitos a serem explorados;

c) determinam as responsabilidades de cada membro do grupo, os prazos, as fontes de pesquisa etc.;

d) chegando a uma solução satisfatória, apresentam-na e a defendem perante a turma e o tutor; e finalmente

e) avaliam o processo, a si mesmos e o grupo. 


\section{Metodologia}

Este relato de experiência é parte de uma pesquisa de natureza descritivo-analítica realizada com fins de intervenção e exploração sobre a aprendizagem baseada em problemas ou PBL (problem-based learning). Adotou-se a pesquisa qualitativa por esta ser indicada quando se deseja dar voz aos atores, i.e., quando se objetiva compreender um fenômeno a partir dos significados que eles the conferem (DENZIN; LINCOLN, 1994). Sobretudo, o delineamento da pesquisa em questão, i.e., um estudo de caso qualitativo, é particularmente recomendado para a investigação de inovações educacionais (MERRIAM, 1988).

Embora não constitua uma pesquisa colaborativa nos moldes descritos por Cole e Knowles (1993), esta investigação também contemplou a colaboração entre os atores, o docente responsável pelas disciplinas nas quais o PBL foi adotado e o pesquisador acadêmico. Além de o docente ter participado do estudo voluntariamente, ambos contribuíram para a experiência - conforme a disponibilidade de cada um e dentro de suas respectivas áreas de especialização - durante as fases de planejamento, implementação e avaliação da metodologia. Essa colaboração se estendeu também à análise e publicação de alguns dos resultados.

Durante a aplicação do PBL, o pesquisador atuou como observador participante - i.e., apesar de presente nas aulas, estava apenas parcialmente envolvido, de modo a funcionar como investigador (MERRIAM, 1988) - e o docente era responsável pela condução dos trabalhos na sala de aula. Dada a natureza diversa dos papéis desempenhados pelos autores, alguns objetivos investigativos por vezes diferiam, embora, fossem interligados e compartilhados. Essa interação entre os atores, i.e., docente-pesquisador e pesquisador acadêmico, foi fundamental para a consecução dos objetivos da pesquisa.

$\mathrm{O}$ relato que se segue refere-se à experiência com o PBL no contexto em consideração, desde 2002. A metodologia continua sendo empregada pelo docente. O relato traz, especialmente, o ponto de vista de um introdutor de um novo método de ensino-aprendizagem, i.e., a perspectiva do docente responsável pelas disciplinas em que o PBL foi empregado. Embora a pesquisa realizada tenha a figura do pesquisador acadêmico, distinta do professor-pesquisador, este artigo tem por principal objetivo dar voz ao gestor das atividades em sala de aula.

\section{Adoção do PBL na avaliação de um professor de administração}

A experiência ocorreu numa escola de engenharia de uma universidade pública, em diversos cursos de graduação em engenharia e em disciplinas de pós-graduação. Todas as disciplinas tinham conteúdos de administração - especificamente, de "teoria geral da administração" - e "introdução à administração". A metodologia utilizada no ensino dessas disciplinas poderia ser denominada de "aprendizagem baseada em problemas", pois problemas relativos a esses conteúdos foram usados para incentivar sua assimilação pelos alunos, que dessa forma tornavam-se atores ativos no processo ensino-aprendizagem.

O formato do PBL que foi adotado seria denominado parcial em razão de seu emprego em disciplinas isoladas dentro de currículos convencionais. As disciplinas compreendiam um encontro semanal de 100 minutos ou 200 minutos (pós-graduação). A dinâmica da aula estava fundamentada em ciclo semanal de apresentação de problemas aos alunos, conforme ilustra a Figura 1. Observa-se que a definição de aula entendida como duração de encontro presencial com horário estabelecido pela instituição não coincidia com a aula entendida como duração do estudo de um problema. O ciclo de trabalho com um dado problema iniciava na segunda parte de uma aula e terminava na primeira parte da outra aula. 


\section{Figura 1 - Exemplo de ciclos semanais de aula e problema}

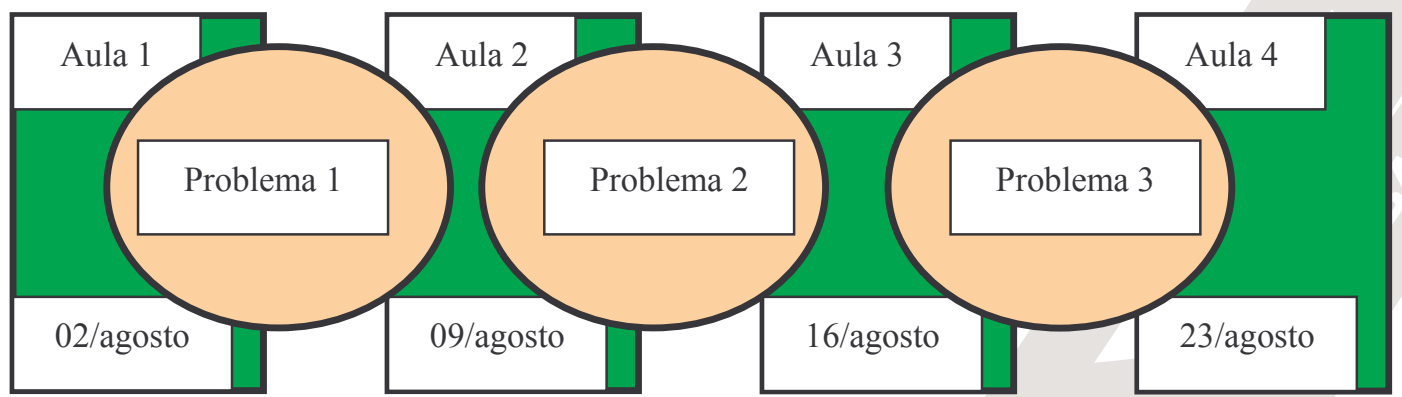

Fonte: elaboração própria

O ciclo de trabalho com o problema, semelhante ao descrito anteriormente, começava com a proposição do novo problema. Ao final dessa aula, os alunos deviam elaborar um relatório parcial, em formulário padronizado, contendo os passos da metodologia de solução de problemas, a saber: causas prováveis do problema, busca de fatos para as causas ou sua eliminação, definição do problema, agenda de questões para pesquisa e para solução dos problemas e o cronograma de trabalho do grupo para a semana subseqüente.

Os problemas trabalhados eram, na verdade, situações-problema que possibilitavam a identificação de problemas diferentes. O PBL permite que os alunos vejam a mesma situação por diferentes ângulos e proponham soluções diversificadas, o que tem sido um ponto de destaque do método e de satisfação dos alunos. Os problemas poderiam ser mais bem definidos como narrativas escritas sobre situações problemáticas contextualizadas.

Muitas dessas situações diziam respeito a um contexto temporal e histórico definido, sendo, portanto, esperadas soluções compatíveis com a data, os eventos, os lugares e os personagens referentes à descrição do problema. Um exemplo de problema seria: "Estamos em 1938, nos Estados Unidos da América, você é o diretor de pessoal e ouve o presidente da empresa: 'Nossa empresa tem milhares de funcionários e emprega as melhores técnicas de administração atualmente conhecidas no mundo. Todo trabalhador é cientificamente selecionado, treinado para trabalhar isoladamente e sem interferência dos outros funcionários e recebe um ótimo incentivo salarial por produção realizada dentro do padrão estabelecido pela gerência. O ambiente físico é muito bem cuidado e o ritmo do trabalho, sistematicamente estabelecido. No entanto, os trabalhadores faltam muito, deixam nossa empresa como se não nos preocupássemos com eles e ainda andam indo aos sindicatos e fazendo greves. Onde está a lealdade com a empresa? Até os governantes parecem ser comunistas! Falam muito num Estado do Bem-Estar Social e aprovaram leis de assistência social aos idosos, de direitos dos sindicatos, de garantia de salário e até de seguro desemprego!' O presidente inclinou-se em sua direção e perguntou: 'Você acha que nosso incentivo salarial é baixo e devíamos aumentá-lo?",

\section{Aprender a aprender: o papel ativo dos alunos na aprendizagem}

Diferentemente do modelo McMaster, onde cada grupo de 8-12 alunos conta com a supervisão de um tutor, nessa adoção do PBL os alunos trabalhavam em grupos autogeridos de 4 ou 5 membros. O docente assumiu um papel denominado de "facilitador flutuante", pois durante as atividades de sala de aula, circulava entre os grupos, trazendo à tona conhecimentos prévios, tirando dúvidas, questionando entendimentos equivocados e incentivando os alunos a se aprofundarem na resolução do problema. Um esquema da aula com o PBL no contexto em questão é dado pela tabela 1. 
Tabela 1 - Esquema de aula do caso relatado

\begin{tabular}{|c|c|c|c|}
\hline $\begin{array}{l}\text { Segmento da } \\
\text { aula }\end{array}$ & Tempo & $\begin{array}{l}\text { Dinâmica da } \\
\text { aula }\end{array}$ & Ciclo do problema \\
\hline \multirow{3}{*}{1} & \multirow{3}{*}{$5-10 \%$} & \multirow{3}{*}{$\begin{array}{l}\text { Centrada no } \\
\text { professor }\end{array}$} & Conversa informal para quebrar o gelo \\
\hline & & & Devolução de material corrigido \\
\hline & & & $\begin{array}{l}\text { Comentários sobre os trabalhos dos alunos e aspectos } \\
\text { metodológicos }\end{array}$ \\
\hline \multirow{2}{*}{2} & \multirow{2}{*}{$30-40 \%$} & \multirow{2}{*}{$\begin{array}{l}\text { Centrada nos } \\
\text { alunos }\end{array}$} & $\begin{array}{l}\text { Apresentação dos trabalhos dos grupos à classe, relativos ao } \\
\text { problema anterior }\end{array}$ \\
\hline & & & Entrega dos relatórios finais \\
\hline \multirow{2}{*}{3} & \multirow{2}{*}{$30-40 \%$} & \multirow{2}{*}{$\begin{array}{l}\text { Centrada no } \\
\text { professor }\end{array}$} & Debate entre professor e alunos \\
\hline & & & Síntese do professor \\
\hline \multirow{2}{*}{4} & \multirow{2}{*}{$5-10 \%$} & \multirow{2}{*}{$\begin{array}{l}\text { Centrada nos } \\
\text { alunos }\end{array}$} & $\begin{array}{l}\text { Avaliação do problema e processo educacional (todos os } \\
\text { membros do grupo) }\end{array}$ \\
\hline & & & $\begin{array}{l}\text { Auto-avaliação e avaliação dos membros dos grupos (somente } \\
\text { pelos líderes) }\end{array}$ \\
\hline \multirow{2}{*}{5} & \multirow{2}{*}{$15-30 \%$} & \multirow{2}{*}{$\begin{array}{l}\text { Centrada nos } \\
\text { alunos }\end{array}$} & Apresentação do novo problema \\
\hline & & & Entrega do relatório parcial \\
\hline
\end{tabular}

Fonte: elaboração própria

Evidentemente, a aprendizagem dos grupos não era totalmente livre, já que a escolha dos problemas, o contorno dos temas, os prazos, os formatos dos relatórios, as formas de apresentação dos resultados, os critérios de avaliação e outros aspectos instrucionais estavam sob a responsabilidade do professor. De qualquer forma, havia um desafio de aprendizagem colocado aos alunos por meio dos problemas, onde um alto grau de liberdade e de criatividade era propiciado, o que diferenciava a aula com o PBL do ensino tradicional através de aula expositiva.

Nos grupos, os alunos assumiam, alternadamente, os papéis de líder, redator, porta-voz e de membro participante do grupo. O objetivo era colocá-los em situações reais, embora simuladas, da vida profissional, nas quais os administradores gerenciam, preparam relatórios escritos, fazem apresentações orais e trabalham em grupo.

A vivência nesses anos de uso do PBL permitiu a formulação de estratégias de formação dos grupos, tal como, permitir, na primeira metade da disciplina, a livre escolha pelos membros, e na segunda metade, a formação de equipes de trabalho. Os grupos tiveram fundamentação na amizade e na afinidade afetiva; já as equipes, nas especialidades para o alto desempenho e, principalmente, no rompimento das "panelinhas".

A observação do trabalho dos alunos com os problemas indica que estes aprendem a aprender de forma autônoma e colaborativa com o PBL. Um ponto central é a aprendizagem pela pesquisa de conceitos de administração para solucionar os problemas propostos pelo professor. Os alunos são estimulados a consultar livros, periódicos, jornais, revistas, Internet, professores, profissionais e colegas de faculdade. 


\section{Mudança no papel do professor: de expositor a facilitador}

No ensino tradicional, o professor é um expositor com as rédeas seguras da condução da aula. Nesse sentido, são comuns relatos de alunos que se dizem inibidos com as práticas docentes adotadas. É que nesse caso, o professor é planejador e executor do ensino e seus alunos, meros espectadores, não importando se aprendem ou não, pois a aula é um monólogo. O professor prepara e ministra o conteúdo programático sem que haja questionamentos, uma que não precisa se preocupar com a interação entre e com os alunos, já que ela não existe.

No PBL, o professor é facilitador de um processo de aprendizagem em que o aluno exerce um papel ativo, o que exige do docente grande esforço e comprometimento. O professor prepara problemas com situações administrativas que desafiam a curiosidade e promovem a motivação espistêmica dos alunos, i.e., seu desejo de conhecimento. Isso implica que nem sempre as resposta são as esperadas pelo professor. Há sempre um grau de imprevisibilidade na condução da aula; um conteúdo não programado pode aparecer na discussão dos problemas. Entretanto, também é um momento de auto-aprendizado. Aqui, professor também aprende administração.

Outro ponto importante é a gestão das relações em sala de aula. É comum que ocorram conflitos, especialmente, quanto à formação de equipes, ao exercício da liderança, à avaliação e ao trabalho colaborativo. $\mathrm{O}$ ambiente educacional na sala de aula PBL permite o diálogo entre os alunos e destes com o professor. Este não é, simplesmente, um caldeirão de sabedoria, mas um facilitador de oportunidades de aprendizagem, alguém que estimula o desenvolvimento de habilidades.

\section{E tudo isso é bom? A experiência com o PBL no ensino de administração}

A avaliação geral do professor aponta que o método PBL é uma alternativa muito boa de ensino-aprendizagem. Para o formato parcial adotado, de disciplina isolada em currículo tradicional, ainda é possível contemplar a alternativa de combinar aulas expositivas com o trabalho com problemas. Esse ponto de vista do professor está de acordo com a avaliação geral dos alunos levantada pelo pesquisador: $90 \%$ deles, nas quatro turmas analisadas, consideraram o PBL positivo para sua aprendizagem.

A exposição do conteúdo não foi eliminada pelo professor, mas teve um tempo menor, como pode ser visualizado na tabela 1, no segmento 3 da aula. Observe-se que o tempo não é ínfimo, algo em torno de 30\%$40 \%$ da duração dos encontros semanais. Mesmo assim, alguns alunos manifestaram o desejo de que o professor tenha um posicionamento mais claro sobre os conceitos estudados, pois para eles, o professor ainda é a fonte segura de informação. Essa postura provavelmente decorre de uma socialização em ambientes educacionais mais diretivos e de estratégias pessoais bem sucedidas na lida com as demandas das disciplinas, mas isso não foi possível precisar.

De qualquer forma, os alunos não estão de todo sem razão. Para o professor, no formato em que foi aplicado, o PBL favorece a amplitude do conteúdo em detrimento de sua profundidade. Para detalhar os temas, o professor precisaria repetir o ciclo com novos problemas para o mesmo tema ou, ainda, trabalhar com o mesmo problema até atingir a profundidade conceitual desejada. Em termos de cumprimento de um programa preestabelecido, isso implicaria sacrificar alguns tópicos de modo a tratar outros com maior profundidade.

Por outro lado, essa dificuldade está associada a aspectos institucionais, tais como o baixo número de créditos da disciplina e a pesada grade semestral (em torno de 26 horas em sala) etc. Ademais, o PBL é um método de ensino-aprendizagem pautado pela construção do conhecimento pelo aluno, com orientação do professor, com maior afinidade com os estudos pós-graduados. $\mathrm{Na}$ aula expositiva na graduação, geralmente, não há "perda de tempo" com a reflexão do aluno; uma síntese especializada, individualizada e fortemente controlada é conduzida pelo professor, contando com a aquiescência intelectual dos alunos.

Para o professor trabalhando com o PBL, o maior sentimento foi de vulnerabilidade diante dos imprevistos. No método tradicional, o professor programa a disciplina, a aula, o conceito a ser estudado; o desvio do programado é quase inexistente. No PBL, as soluções dos problemas trazem perspectivas e conceitos não 
programados pelo professor, fonte de imprevisibilidade na aula, embora isso possa ser minimizado com a entrega antecipada dos relatórios finais antes da apresentação das soluções e do encerramento do ciclo de trabalho com o problema.

Esse aspecto tem um lado positivo, na medida em que os alunos revelam diversidade de olhares sobre o problema. O que seria mais rico e real para o estudante de administração do que deparar-se com várias soluções diferentes para o mesmo problema? Não seria esta uma situação típica em empresas? Sobretudo, esta não seria também uma oportunidade de aprendizagem contínua para o professor, de aprender com a sala de aula e um estímulo constante para a busca de aperfeiçoamento conceitual?

Há, ainda, um componente afetivo importante: com o PBL, a interação entre os alunos e entre os alunos e o professor é muito maior. Ao se aproximar dos alunos, descendo de seu tablado, o professor reconhece as características humanas de seus companheiros de jornada. Pessoas como o professor, com qualidades e defeitos, com sonhos e desesperos particulares; aspectos eliminados no ensino tradicional e positivista de ver a realidade como uma construção social dada e não a ser construída.

\section{Considerações finais}

É desnecessário dizer que o PBL não é panacéia para todos os males que acometem o ensino superior, em administração ou em outro campo de conhecimento. Também não oferece garantia de colocação no mercado de trabalho ou uma carreira bem-sucedida para os alunos que são formados através dela.

O PBL não fornece, tampouco, um ambiente de aprendizagem satisfatório para todos os alunos e professores. É sabido que alunos têm diferentes estilos de aprendizagem e que alguns podem não se adaptar a um ambiente de aprendizagem autodirigida e colaborativa. Sabe-se também que a maioria dos alunos que conseguem chegar às universidades, especialmente as públicas, vem diretamente de modelos educacionais que promovem a recepção passiva de conhecimentos, estão acostumados a depender do professor como fonte de conceitos teóricos fixos e acabados.

Por outro lado, o PBL parece não ser um modelo instrucional que serve a todos os docentes. Os professores universitários, mormente os das universidades públicas, têm atividades outras além do ensino. O PBL demanda mais dedicação docente, o que pode prejudicar atividades mais valorizadas, tais como pesquisa e publicações. Ademais, muitos professores são, eles próprios, vencedores nos modelos tradicionais de ensino e, assim, podem não conseguir ver a necessidade de mudanças didáticas em suas aulas.

No entanto, o PBL, mesmo quando adotado parcialmente, como no estudo em questão, parece ser vantajoso em comparação com abordagens instrucionais expositivas. Apesar de implicar certo grau de imprevisibilidade e de exigir maior tempo de dedicação, o PBL parece contribuir bastante não apenas para que o docente se sinta mais satisfeito com as atividades de ensino, mas também para estimular seu aperfeiçoamento profissional mediante os desafios intelectuais que lhe são colocados pelos alunos. Ao menos, é o que indica esta pesquisa, confirmada pela continuidade do uso do PBL nas disciplinas sob responsabilidade do professor/autor. 


\section{Referências}

DEWEY, J. My pedagogic creed. In: ARCHAMBAULT, R. D. (Ed.). John Dewey on education: selected writings. New York: The Modern Library, 1964, p.427-439.

BARROWS, H. S. Problem-based learning in medicine and beyond: a brief overview. In: WILKERSON, I.; GIJSELAERS, W. H. (Ed.). Bringing problem-based learning to higher education. San Francisco: Jossey-Bass, 1996. p.3-12.

BRUNER, J. S. Uma nova teoria da aprendizagem. Rio de Janeiro: Bloch Editores, 1973.

COLE, A. L; KNOWLES, J. G. Teacher development partnership research: a focus on methods and issues. American Educational Research Journal, v. 30, n.3, p.473-495, 1993.

DENAYER, I. et al. Teaching a structured approach to the design process for undergraduate engineering students by problem-based education. European Journal of Engineering Education, v.28, p.203-214, 2003.

DENZIN, N. K.; LINCOLN, Y. S. Entering the field of qualitative research. In: (Ed.). Handbook of qualitative research. Thousand Oaks: Sage, 1994. p.1-17.

DUCH, B. J.; GROH, S. E.; ALLEN, D. E. (Ed.). The power of problem-based learning. Sterling: Styllus, 2001.

FREIRE, P. Educação e mudança. Rio de Janeiro: Paz e Terra, 1981.

INTERNATIONAL PBL CONFERENCE 2006. Lima, Peru. Disponivel em: <http://www.pucp.edu.pe/eventos/congresos/pbl2006abp/i08.htm>. Acesso em: 1 jul. 2007.

KINGSLAND, A. Problem-based learning: efficient, affordable, and stress-free implementation. In: RYAN, G. (Ed.). Research and development in problem-based learning. Sydney: University of Sydney-MacArthur Press, 1993. v.1. p.311-319.

MERRIAM, S. B. Case study research in education: a qualitative approach. San Francisco: Jossey-Bass, 1988.

RIBEIRO, L. R. C. Aprendizagem baseada em problemas (PBL): uma experiência no ensino superior. São Carlos: EdUFSCar, 2008.

SAVIN-BADEN, M. Problem-based learning in higher education: untold stories. Buckingham: Open University Press, 2000.

STINSON, J. E.; MILTER, R. G. Problem-based learning in business education: curriculum design and implementation issues. In: WILKERSON, I.; GIJSELAERS, W. H. (Ed.). Bringing problem-based learning to higher education. San Francisco: Jossey-Bass, 1996. p.33-42. 